\title{
LIII. Remarks on the weather during the quarter ending March 31, 1849
}

\section{James Glaisher Esq.}

To cite this article: James Glaisher Esq. (1849) LIII. Remarks on the weather during the quarter ending March 31, 1849, Philosophical Magazine Series 3, 34:230, 366-374, DOI: 10.1080/14786444908562665

To link to this article: http://dx.doi.org/10.1080/14786444908562665

册 Published online: 30 Apr 2009.

Submit your article to this journal

Џ Article views: 2

Q View related articles $\sqsubset$ 
ascribes to the air of preventing the immediate escape of the developed heat or cold be demonstrated. At present this property is hypothetical. The argument contained in this communication would rather point to the inference, that the developed heat or cold instantly passes off in a radiant form, without producing any very appreciable alteration of the state of temperature of the air where it is generated.

The mathematical investigation of the velocity of sound which I have now expounded, originated in an attempt to explain theoretically the polarization of light exclusively on hydrodynamical principles, the wther being treated as a continuous medium, the pressure of which, as in air of given temperature, varies in the same proportion as the density. My views on this subject are contained in several recent communications to the Cambridge Philosophical Society. In the course of the inquiry I found that the velocity of propagation in such a medium was not the value $a$, as generally supposed, but a certain greater quantity $a \sqrt{\mathrm{l}+k}$, and that the explanation of the phrenomena of polarization essentially depended on this result. I: was clearly, therefore, important to obtain a numerical value of $a \sqrt{1+k}$ which could be tested by actual observation of the velocity of sound. This I consider that I have now done, and that I have thus removed an objection which otherwise might have been urged against the proposed theory of the polarization of light.

Cambridge Observatory, April 18, 1849.

LIII. Remarks on the Weather during the Quarter ending March 31, 1849. By James GLaisher, Esq., of the Royal Observatory, Greenwich*.

TTHE meteorological returns for the past quarter furnished 1 to the Registrar-General and myself have been received from thirty-four different places, whose returns have passed the necessary examination. The observations generally indicote a decided improvement, having been made for the most part by experienced observers, who have generally paid more attention to their instruments than hitherto. The results are therefore found to be more accordant with each other than any previously received.

Till January 7 and after March 18, the temperature of the air was below its average value; the mean amount of the deficiency of daily temperature in the former period was $6^{\circ} .9$, and in the latter it was $3^{\circ} \cdot 7$.

- Communicated by the Author. 
The interval of time between January 8 and March 17 was distinguished by very unusual warmth for the senson. The average daily excess of temperature within this period was $6^{\circ} \cdot 1$; on four of the days this exceeded $12^{\circ}$, on three days it exceeded $13^{\circ}$, and on two days it was greater than $14^{\circ}$.

The mean temperature of the three months ending February, constituting, in fact, the three winter months, was $42^{\circ} \cdot 5$, being no less than $4^{\circ} .7$ above the average temperature of the same time for seventy years. 'The warmest winters within this period were those ending February 1796, 1822, 1834 and 1846, and which were $43^{\circ} \cdot 2,42^{\circ} \cdot 4,43^{\circ} \cdot 0$ and $43^{\circ} \cdot 2$ respectively.

The pressure of the atmosphere during the month of $\mathrm{Fe}-$ bruary was very unusual. The average reading of the barometer from the 1 st of February till the 18th was 30.36 inches at the height of 160 feet: this was fully half an inch above its average value. This denotes an increase in the volume of air of abont one-sixtieth part above the usual quantity. On the 11 th day the very unusual reading of 30.715 inches took place. The true reading for the whole day, reduced and corrected to $32^{\circ}$ Fahrenheit, was 30.695 inches, showing that about one-thirtieth more than the usual quantity of air wns over England on this day. The reading of the barometer on the 1 I th day, reduced to the level of the sea, was 30.91 inches. In December 1778 the reduced reading was 30.90 inches; in January 1825 it was 30.92 inches \pm .

The condition of the atmosphere, therefore, during the greater part of the past quarter, both with respect to pressure and heat, has been very unusual.

From the discussion of the observations which have been made at the Apartments of the Royal Society since 1774, there appears to be no foundation for the opinion that a hot summer either precedes or follows a cold winter; on the contrary, the hot summers have for the most part been accompanied by warm winters.

From the long continuance of high temperatures, it would seem that for some time past causes have been in operation which have raised the temperature: these causes probably still exist, and therefore there seems to be every probability of a fine and warm summer.

I proceed now to detail the results of the several subjects of research in the past quarter.

The mean temperature of the air-

For the month of January was $40^{\circ} \cdot 1$, exceeding the average of seventy years by $4^{\circ} \cdot 3$. The temperatures in this month in the years $1775,1796,1804,1806,1819$ and 1834, were those only which exceeded that of this year. In the year 1796 it was $45^{\circ} \cdot 4$, being the warmest on record; 
For the month of February was $43^{\circ} \cdot 2$, exceeding the average of the preceding seventy years by $4^{\circ} \cdot 7$. The temperature of this month in the year 1779 was $45^{\circ} \cdot 2$, being the only instance within the period of seventy years in which the temperature exceeded that of this year;

For the month of March was $42^{\circ} \cdot 5$, exceeding the average of seventy years by $1^{\circ} \cdot 2$.

The mean for the quarter was $41^{\circ} \cdot 9$. The average value for seventy years is $38^{\circ} \cdot 6$. In the year 1779 the mean was $42^{\circ} \cdot 0$; in 1822 it was $43^{\circ} \cdot 4$; in 1834 it was $42^{\circ} \cdot 8$; and in the year 1846 it was $43^{\circ} \cdot 6$ : in all the remaining years it was less than $42^{\circ} \cdot 0$.

The excess of temperature above the average of the preceding eight years was in January $3^{\circ} \cdot 0$; in February was $5^{\circ} \cdot 4$; in March was $0^{\circ} \cdot 1$; and for the quarter was $2^{\circ} \cdot 9$.

The mean temperature of evaporation at Greenwich-

For the month of January was $38^{\circ} \cdot 6$; for February was $41^{\circ} \cdot 4$; and for March was $39^{\circ} \cdot 8$. These values are $2^{\circ} \cdot 0$ above, $6^{\circ} \cdot 2$ above, and $0^{\circ} \cdot 3$ below, respectively, the averages of the preceding eight years.

The mean value for the quarter was $39^{\circ} \cdot 9$, which is $2^{\circ} \cdot 6$ above that of the average of eight years.

The mean temperature of the dero-point at Greenroich-

For the months of January, February and March, were $36^{\circ} \cdot 4$, $38^{\circ} .8$, and $36^{\circ} \cdot 5$. The average values for the preceding eight years were $35^{\circ} \cdot \mathrm{l}, 34^{\circ} \cdot 5$, and $36^{\circ} \cdot 6$.

The mean value for the quarter was $37^{\circ} .2$, which is $1^{\circ} .8$ above the average for the preceding eight years.

The mean elastic force of vapour for the quarter was $0.23 y$ inch, which is 0.012 inch greater than the average for the preceding seven years.

The mean weight of water in a cubic foot of air for the quarter was 2.8 grains, which is 0.1 grain greater than the average of the preceding seven years.

The mean additional reeight of roater required to saturate a cubic foot of air was 0.6 grain. This value for the preceding seven years was 0.38 grain.

The mean degree of laumidity in January was 0.883 , in February was 0.863 , and in March was 0.801 . The averages for the seven preceding years were $0.90 \%, 0.888$, and 0.841 . The mean value for the quarter was 0.849 , which is 0.028 less than the average for these years. These values denote a considerable degree of dryness in these months.

The mean reading of the barometer at Greenwich in January was 29.771 inches, in February was 30.106 inches, and in March was 29.915 inches; these values are 0.005 inch above, $0 \cdot 415$ inch $a b o v e$, and $0 \cdot 186$ inch above respectively the averages of the same months for the preceding eight years. 
The reading for the month of February, exceeding 30.1 inches at the height of 160 feet, is very remarkable. Since the year 1774 there have been eight such instances only: these occurred in July 1800, April 1801, November 1805, April 1817, February 1821, January 1825, December ] 834, and December 1843.

The average roeight of a cubic foot of air under the average temperature, humidity, and pressure, was 549 grains; the average for the seven preceding years was 546 grains.

The rain fallen at Greenwich in January was 1.6 inch ; in February was 2.2 inches; and in March was 0.5 inch. The amount for the quarter was 4.24 inches. The average amount for the preceding eight years was $5 \cdot 14$ inches.

The temperature of the water of the Thames was $43^{\circ} .8$ by day, and $42^{\circ} \cdot 1$ by night. The water, on an average, was $1^{\circ}$ warmer than the air.

The direction of the wind at Greenwich from January 1 to 6 was N.E.; from January 7 to 28 was S.IV.; on January 29 was N.N.W.; from. January 30 to March 7 was at times variable, but chiefly S.W.; from March 8 to 17 was mostly N.W.; from March 18 to 28 was chiefly N.E.; and afterwards it was mostly S.S.W. to the end of the month.

At Leicester the direction of the wind was S.W. during seventy-six days within the quarter.

The daily horizontal movement of the air from January 1 to 6 was about 90 miles; the greatest value was 200 miles; from January 7 to 28 was 240 miles; the greatest was 500 miles; and from January 30 to March 28 it was 110 miles; the greatest was 320 miles. The movement of the air in the month of March was small.

The average daily ranges of the thermometer in air at the height of four feet, were $10^{\circ} .8$ in January, $12^{\circ} .9$ in February, and $13^{\circ} .8$ in March. The average ranges for these three months, from the observations of the eight preceding years, were $8^{\circ} \cdot 1,9^{\circ} \cdot 6$, and $13^{\circ} \cdot 4$ respectively.

The readings of the thermometer on grass in January were below $20^{\circ}$ on three nights, the lowest was $17^{\circ}$; at and below $32^{\circ}$ on fourteen nights; between $32^{\circ}$ and $40^{\circ}$ on six nights; above $40^{\circ}$ on six nights; and on one night it was $50^{\circ}$.

In February the lowest reading was $20^{\circ}$, and the readings were below $32^{\circ}$ on eleven nights; between $32^{\circ}$ and $40^{\circ}$ on eight nights, and above $40^{\circ}$ on seven nights. In March the lowest reading was $21^{\circ}$; and the readings were below $32^{\circ}$ on sixteen nights; between $32^{\circ}$ and $40^{\circ}$ on twelve nights; and above $40^{\circ}$ on three nights.

The mean amount of cloud was $7 \cdot 5$, being the same as the average for the preceding eight years.

Phil. Mag. S. 3. Vol. 34. No. 230. May 1849. 
There were nine exhibitions of the aurora borealis during the quarter ending March 31, 1849, which occurred on January 14, and were seen at Aylesbury, Whitehaven and Maidenstone Hill; on January 15 at Hartwell; on February 18 at Wakefield; on the 19th at Stone, Whitehaven and Wakefield; on the 20th at Whitehaven, Hartwell and Greenwich; on the 21 st at Hartwell; on the 22nd at Holkham, Aylesbury, Stone, Norwich, Newcastle and Greenwich; on the 23rd at Whitehaven and Hartwell; and on March 18 at Stone.

Thunder-storms occurred on January 10 at Whitehaven; on January 14 at Norwich; on February 25 at Truro; and on March $B 1$ at Uckfield.

Hail fell at Norwich and Hartwell on January 14 ; at Newcastle on February 22 ; at Wakefield on February 23; at Saffron Walden on March 8.

Snow fell at Saffron Walden on January 4; at Leicester, Saffron Walden, Highfield House, and Southampton on January 5 ; at Saffron Walden on January 29 ; at Stone, Hartwell, Norwich, and Saffron Walden on February 28 ; at Stone and Saffron Walden on March 24 and 25 ; at Stone on the 28th; and at Norwich on the 31st.

Solar halos were seen at Greenwich on February 26 and on March 30.

Lunar halos were seen at Greenwich on January 6, and at Stone on February 27, March 7, 8 and 31.

Zodiacal light was seen at Whitehaven on February 11.

The reading of the barometer was above 30 inches on the 1st of January; it decreased to 29.58 by the $3 \mathrm{rd}$, and increased to 29.93 by the 6 th. During the evening of the 7th it decreased quickly, and was $29^{\circ} 4$ on the 8 th and 9 th. On the loth the lowest reading in the month took place, and was 28.83 ; on the 11 th it increased rapidly, and was 29.85 at midnight, and passed the point 30 early on the morning of the 12th. On the 13th and 14th the readings decreased, and were 29.31 on the latter day, and then it increased with slight exceptions till the evening of the $23 \mathrm{rd}$, when the reading was 30.328 , being the highest during the month; it then decreased, slowly at first, and rapidly during the afternoon of the 27 th. The reading was 29.26 on the evening of the $28 \mathrm{th}$, after which it increased, and was $30^{\circ} 16$ at the end of the month. In February the average reading from the 1 st to the 18 th was 30.36 . On the 11 th, in the evening, the very extraordinary reading of 30.715 took place. On the 19 th the reading descended below 30 inches; on the 20 th the decrease was 0.4 ; on the 21 st and $22 n d$ the reading was about 29.7 ; on the 24 th and 25 th the decrease both days was about 0.25 , and the reading was 29.21 on the evening of the 25 th ; it increased 0.5 
on the $26 \mathrm{th}$, and still further increased 0.25 on the 27 th. The reading at this time was 29.91 at midnight. On the 28th it decreased rapidly, and was 29.20 at midnight, being the lowest in the month. The range within this month was 2.52 inches.

On the 2nd of March the reading passed the point 30 inches, and on the 6th the highest reading in the month took place, viz. 30.48; after this the changes were small till the 26th, the reading being above its average value. On the 27 th the reading decreased half an inch, and on the 28th the lowest reading took place in the month, 29.18 , and it remained low till the end of the month.

The reading of the barometer on February 11 at Aylesbury was 30.369 ; at Leicester was 30.800 ; at Durham was 30.440 ; at Whitehaven 30.62 ; at Newcastle was 30.764 ; at Exeter was 30.838 ; at Liverpool was 30.861 ; at Truro was 30.74 ; at Norwich was 30.910 ; and at Cardington was 30.846 .

The monthly mean values of the several subjects of investigation are shown in the Registrar-General's report.

The observations have been corrected for diurnal ranges, and the results are all comparable with each other.

The observer al Southampton has kindly furnished me with the following agricultural report for Hampshire, the particulars having been supplied by John Clark, Esq., of Finsbury Farm, near Romsey.

"The weather during the quarter has been most propitious for cropping. The fine dry March, followed by the gentle showers of April, have benefited to a great degree both the soil and cattle. Sowing is in a forward state, and young wheat looks well.

"The lambing season is over, and it is believed will prove to be an average. Some strange anomalies have been prevalent. On adjacent farms no loss has been experienced in one, whilst the loss both of ewes and lambs have been great in the other."

Themean of the numbers in the first column of the subjoined table is 29.837 inches, and this value may be considered as the pressure of dry air for England during the quarter ending March 31, 1849. The differences between this number and the separate results contained in the first column show the probable sums of the errors of observation and reduction; the latter arising partly from erroneously assumed altitudes, and partly from the index errors of the instruments not having been determined. In most cases the sums of these errors are small.

The mean of the numbers in the second column, for Guernsey and those places situated in the counties of Cornwall and Devonshire, is $45^{\circ} .2$; for those places situated south of latitude $2 \mathrm{~B} 2$ 


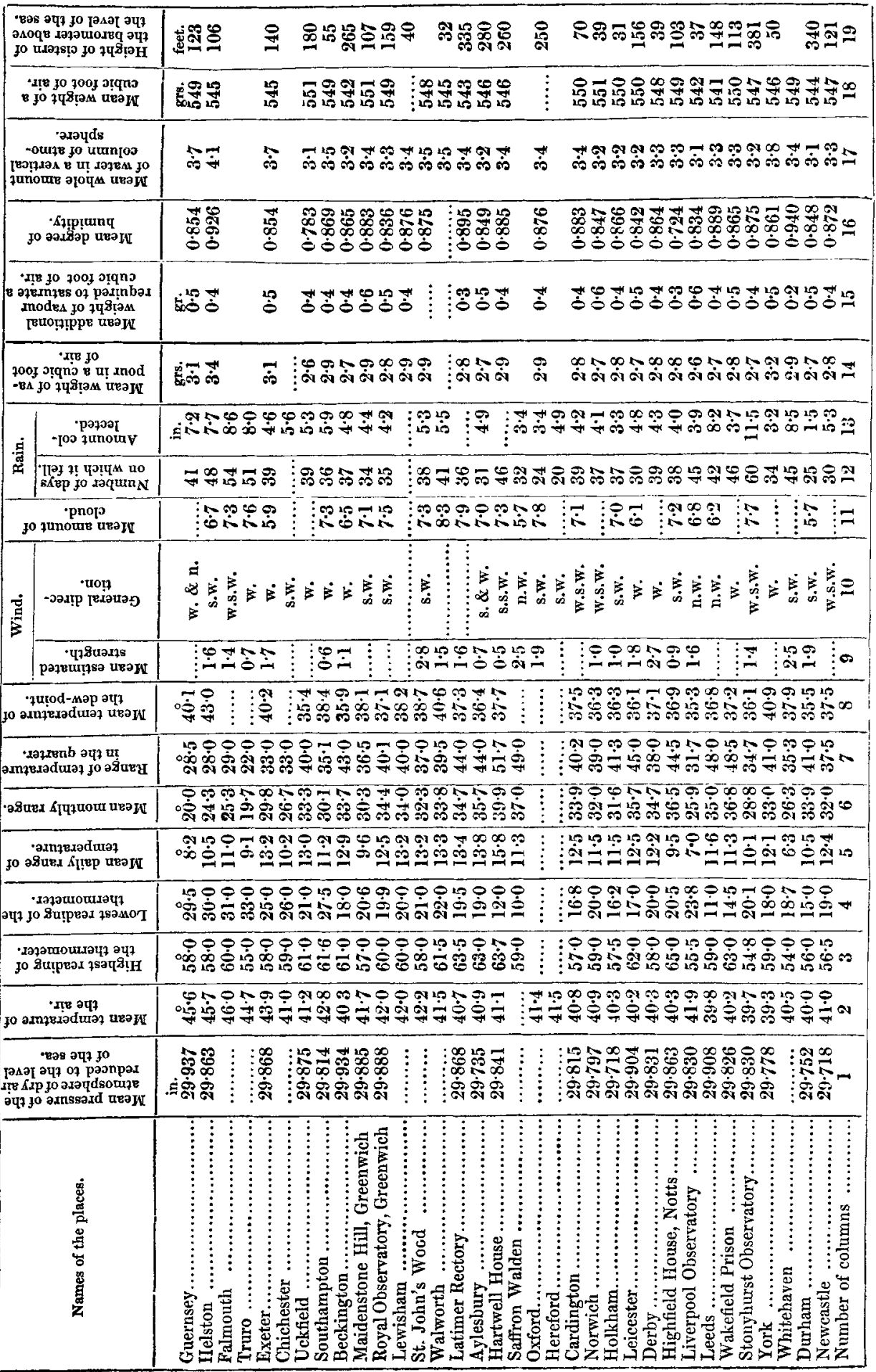


of $52^{\circ}$, including Chichester and Hartwell, is $41^{\circ} \cdot 4$; for those places situated between the latitudes of $52^{\circ}$ and $53^{\circ}$, including Saffron Walden and Leicester, is $40^{\circ} .7$; for those places situated between the latitudes of $53^{\circ}$ and $54^{\circ}$, including Derby and York, is $4.0^{\circ} .2$; and for Whitehaven, Durham and Newcastle is $40^{\circ} \cdot 5$. These values may be considered as those of the mean temperatures of the air for those parallels of latitude during the quarter ending March 31, 1849.

The average daily range of temperature in Cornwall and Devonshire was $10^{\circ} \cdot 4$; at Liverpool and Whitehaven was $6^{\circ} \cdot 7$; south of latitude $52^{\circ}$ was $12^{\circ} \cdot 6$; between the latitudes of $52^{\circ}$ and $54^{\circ}$ was $11^{\circ} \cdot 5$; and at Durham and Newcastle was $11^{\circ} \cdot 5$.

The greatest mean daily ranges of the temperature of the air took place at Hartwell, Aylesbury, and Latimer; in fact, in and near the vale of Aylesbury; and the least occurred at Whitehaven, Liverpool and Guernsey.

The highest thermometer readings during the quarter were $65^{\circ}$ at Highfield House, $63^{\circ} \cdot 7$ at Hartwell, and $63^{\circ} \cdot 5$ at Latimer. The lowest thermometer readings were $10^{\circ} \cdot 0$ at Saffron Walden, $11^{\circ} .0$ at Leeds, and $12^{\circ} .0$ at Hartwell. The extreme range of temperature of the air during the quarter in England was therefore about $55^{\circ}$, most likely somewhat less than this value.

The average quarterly range of the reading of the thermometer in Cornwall and Devonshire was $28^{\circ} .1$; at Liverpool and Whitehaven was $33^{\circ} \cdot 5$; south of latitude $52^{\circ}$ was $40^{\circ} \cdot 3$; and north of $52^{\circ}$ was $42^{\circ} \cdot 1$.

The mean temperature of the dew-point in Cornwall and Devonshire was $41^{\circ} \cdot 1$; south of latitude $52^{\circ}$ was $37^{\circ} \cdot 6$; between the latitudes of $52^{\circ}$ and $53^{\circ}$ was $36^{\circ} \cdot 5$, and north of $53^{\circ}$ was $37^{\circ} \cdot 2$.

The direction of the wind has been mostly south-west; at some few places it seems to have prevailed for some time from the north-west.

From the numbers in the tenth column the distribution of clouds has been such as to cover about three-fifths of the whole sky.

Rain has fallen on the greatest number of days at Wakefield, Falmouth, Truro and Helston. The average number at these places was 53. It fell on the least number of days at Oxford, Saffron Walden, Durham and Leicester, and the average number at these places was 35 . The stations at which the largest falls have taken place were Stonyhurst, Falmouth, Whitehaven and Leeds. The falls were smallest in amount at Durham particularly, York, Holkham and Oxford. The average fall in the counties of Cornwall and Devonshire was $7 \cdot 2$ inches; south of latitude $52^{\circ}$ was $5 \cdot 1$ inches; between 


\section{On Sines and Cosines of Multiples of a variable angle.}

latitudes $52^{\circ}$ and $53^{\circ}$ was 4 inches; and south of $53^{\circ}$, omitting Stonyhurst, was 4.3 inches.

The smallness of the fall at Durham is remarkable; between January 81 and March 28 only 0.14 inch fell.

The numbers in column 14 to 18 show the mean values of the hygrometrical results at every station; from which we find that-

The mean weight of vapour in a cubic foot of air for all places (excepting Cornwall and Devonshire) in the quarter ending March 31, 1849, was 2.8 grains.

The mean additional weight required to saturate a cubic foot of air in the quarter ending March 31, 1849, was 0.4 grain.

The mean degree of humidity (complete saturation $=1$ ) in the quarter ending March 31, 1849, was $0 \cdot 860$.

The mean amount of vapour mixed with the air would have produced water, if all had been precipitated at one time on the surface of the earth, to the depth of 3.3 inches.

The mean weight of a cubic foot of air at the mean height of 160 feet under the mean pressure, temperature and humidity, was 547 grains.

And these values for Cornwall and Devonshire were $3 \cdot 2$ grains; 0.5 grain ; $0.878 ; 3.8$ inches; 547 grains, at the mean height of 120 feet.

Errata.-In the formula for calculating the pressure of dry air, in the last Number of the Magazine, for + read -; and for 82 inches read 820 feet.

For the formula for calculating the weight of a cubic foot of nir, substitute the following:

541 grains $-\left(\frac{\text { height of place in feet above the level of the sea }}{820 \text { feet }} \times 18\right)$

LIV. On the Determination of the Coefficients in any series of Sines and Cosines of Multiples of a variable angle from particular values of that series. By the Rev. Brick Bronwin*. WY last paper in this Journal having been terminated 1 rather in haste, I did not observe that the step contained in (16.) might be repeated. Thus

$$
\begin{aligned}
& \cos (n-1) \frac{i \pi}{n}= \pm \cos \frac{i \pi}{n}, \quad \cos (n-3) \frac{i \pi}{n}= \pm \cos \frac{3 i \pi}{n}, \text { \&c. ; } \\
& \sin (n-1) \frac{i \pi}{n}=\mp \sin \frac{i \pi}{n}, \quad \sin (n-3) \frac{i \pi}{n}=\mp \sin \frac{3 i \pi}{n}, \& \mathrm{c} .
\end{aligned}
$$

Therefore if we make

$$
\begin{array}{ll}
u_{1} \pm u_{\frac{n}{2}}=w_{1}, & u_{2} \pm u_{\frac{n}{2}-1}=w_{2}, \& c_{0} ; \\
v_{1} \mp v_{\frac{n}{2}}=x_{1}, & v_{2} \mp v_{\frac{n}{2}-1}=w_{2}, \& \mathrm{c}_{0} ;
\end{array}
$$

* Communicated by the Author. 